\title{
Taking It Personally: The Effect of Ethnic Attachment on Preferences for Regionalism*
}

\author{
Joan Ricart-Huguet ${ }^{\dagger} \quad$ Elliott Green ${ }^{\ddagger}$
}

November 23, 2016

\begin{abstract}
This paper presents three related findings on regional decentralization. We use an original dataset collected in Uganda to establish, for the first time in a developing country context, that individuals have meaningful preferences over the degree of regional decentralization they desire, ranging from centralism to secessionism. Second, multilevel models suggest that a small share of this variation is explained at the district and ethnic group levels. The preference for regional decentralization monotonically increases with an ethnic group or district's average ethnic attachment. However, the relationship with an ethnic group or district's income is U-shaped: both the richest and the poorest groups desire more regionalism, reconciling interest and identity-based explanations for regionalism. Finally, we show that higher individual ethnic attachment increases preferences for regionalism using fixed effects and a new matching method.

Keywords: Developing countries; African subnational politics; ethnicity; decentralization; federalism.
\end{abstract}

\footnotetext{
*For comments, we thank Scott Abramson, Mark Beissinger, Michael Donnelly, Evan Lieberman, John Londregan, Brandon Miller de la Cuesta, Betsy Levy Paluck, Marc Ratkovic and seminar participants at Princeton University.

${ }^{\dagger}$ Corresponding author. Department of Politics, Princeton University, Princeton, NJ 08540. e-mail: jricart@princeton. edu

${ }_{\ddagger}^{\ddagger}$ Department of International Development, London School of Economics, London WC2A 2AE, UK, e.d.green@lse.ac.uk
} 


\title{
Taking It Personally: The Effect of Ethnic Attachment on Preferences for Regionalism
}

November 23, 2016

\begin{abstract}
This paper presents three related findings on regional decentralization. We use an original dataset collected in Uganda to establish, for the first time in a developing country context, that individuals have meaningful preferences over the degree of regional decentralization they desire, ranging from centralism to secessionism. Second, multilevel models suggest that a small share of this variation is explained at the district and ethnic group levels. The preference for regional decentralization monotonically increases with an ethnic group or district's average ethnic attachment. However, the relationship with an ethnic group or district's income is U-shaped: both the richest and the poorest groups desire more regionalism, reconciling interest and identity-based explanations for regionalism. Finally, we show that higher individual ethnic attachment increases preferences for regionalism using fixed effects and a new matching method.

Keywords: Developing countries; African subnational politics; ethnicity; decentralization; federalism.
\end{abstract}




\section{Introduction}

What explains preferences for regionalism? In particular, is ethnic attachment-how much one prioritizes one's ethnicity over one's national identity - only correlated with or does it actually affect one's preferred power-sharing arrangement? Extant literature posits that preferences for a regional tier of government differs between groups (Horowitz, 1985; Hechter, 1974), such that some groups prefer a federal arrangement while others desire a centralized government. However, there is very little empirical work on this topic, especially in developing countries where researchers have focused instead on the pervasive influence of ethnicity in political economy outcomes. ${ }^{1}$

There has also been much academic and policy debate on constitutional engineering and institutional design in response to territorial cleavages. ${ }^{2}$ Amoretti and Bermeo (2004, p. 11) suggest federalism maximizes political stability by accommodating territorial cleavages. Alesina and Spolaore (2003) suggest decentralization of power away from the central government is a solution to satisfy demands for diverse public goods in ethnically heterogeneous societies. In essence, 'planners' try to determine the optimal institutional design, where optimality involves maximizing some function of interest. Other authors are less optimistic, especially in developing regions such as sub-Saharan Africa. For Roeder (2005, p. 51), long-term stability is maximized by a non-federalist 'power-dividing' arrangement that ensures the rights of ethnic groups through universalistic civil liberties. In a similar mode, developing country scholars believe the "marriage of ethnicity and federalism [to be] unwise because it is bound to exacerbate difficulties sub-Saharan African countries already face" (Selassie, 2003, p. 56).

Unfortunately, articles on institutional design tend to prescribe 'solutions' from a normative or an efficiency view point while ignoring actual preferences of those citizens for whom the institutional design is intended. Designing power-sharing institutions that groups and individuals desire is important, since citizens condition their legitimacy and success. Imposing centralized political systems where at least some regions desire a decentralized arrangement has political risks. Marginalized groups (Horowitz, 1985) and excluded "ethnoregional" groups (Wimmer et al., 2009) sometimes turn to expressing their preferences

\footnotetext{
${ }^{1}$ For example, ethnic diversity undermines economic performance and public good provision (Easterly and Levine, 1997; Habyarimana et al., 2007); ethnic boundary institutions negatively affect government responses to pandemics like HIV/AIDS (Lieberman, 2009); ethnic groups often drive secessionist movements (Horowitz, 1985; Hechter, 2000); and national leaders tend to favor their own ethnic group (Franck and Rainer, 2012; Kramon and Posner, 2016).

${ }^{2} \mathrm{~A}$ territorial cleavage exists when a self-conscious minority is geographically concentrated (Amoretti and Bermeo, 2004, p. 2).
} 
violently, especially in developing and less stable countries where these groups have fought either for more autonomy or secession, such as with East Timor, Mali and South Sudan in recent decades. Not only does the evidence explaining variation in preferences for regionalism remain extraordinarily thin outside Europe and North America, ${ }^{3}$ but also previous scholarship has focused its attention on regions with strong regionalist or secessionist intentions, such as Catalonia or Scotland, rather than on countries as a whole. ${ }^{4}$ The consequence of this dual gap in the literature is that we have very little information on citizen preferences for regionalism in the developing world, as well as very little understanding of how multiple groups or regions within a single country differ in their preferences for regionalism.

We examine citizen preferences for regionalism using original data from a nation-wide representative survey in Uganda, which is an ideal case for three reasons. First, Uganda is very ethnically diverse, even by African standards, and thus allows for group-level analysis in a way that could not be undertaken in other countries with few groups. ${ }^{5}$ Second, Uganda's diversity extends to both language and religion. The country contains speakers of Bantu languages and non-Bantu languages, as well as Muslims, Protestants and Catholics. Third, like in many African countries such as Ethiopia, Kenya and Nigeria, there has long been political debate in Uganda about the implementation of a regional tier of government, which our analysis could help to inform.

We present three related findings on regional decentralization. First, we establish that there is meaningful group and individual variation over the preferred degree of regional decentralization, ranging from centralism to secessionism. Second, multilevel models suggest that a small share of this variation is explained at the district and ethnic group levels: while preference for regional decentralization monotonically increases with a group or district's ethnic attachment, the relationship with a group or district's average wealth is U-shaped. In other words, both the poorest and the richest groups and districts desire more regionalism. These findings reconcile the fiscal federalism and the marginalization logics (Hechter, 1974; Horowitz, 1985; Alesina and Spolaore, 2003; Sambanis and Milanovic, 2011), as we explain below. Third, individual preferences for regionalism can be explained by individual ethnic attachment - there is much within-group variation. We show that prioritizing one's

\footnotetext{
${ }^{3} \mathrm{~A}$ number of recent articles attempt to explain variation in preferences for regionalism in Spain, Belgium, Russia, the UK and the US (Boylan, 2015; Burg, 2015; Dodeigne et al., 2014; Hagendoorn et al., 2008; Muñoz and Tormos, 2015.

${ }^{4}$ The one nation-wide study of preferences for devolution or regionalism comes from a study of Belgian MPs (Dodeigne et al., 2014).

${ }^{5}$ Fearon (2003), for instance, lists Uganda as the third most ethnically fractionalized country in Africa and fourth most in the world. His dataset lists 18 ethnic groups that comprise $1 \%$ or more of the population in Uganda, which is more than any other country in Africa after Tanzania (with 21).
} 
ethnic identity over one's national identity causes a $22 \%$ decrease in the probability of being centralist, while it increases the probability of being a federalist by $23 \%$ and a secessionist by $66 \%{ }^{6}$ Wealth is the other relevant individual factor: richer individuals prefer more regional decentralization. While this article focuses on identity-based explanations, we argue that identity-based and interest-based explanations are not competing but instead can be complementary. ${ }^{7}$

We use two different empirical strategies to identify the effect of individual ethnic attachment on preferences for regional decentralization. Our first strategy is to exploit withinethnicity within-district variation by using fixed effects for ethnic groups and districts in the same model in addition to relevant individual-level controls. Our second strategy takes advantage of a new matching method for general treatment regimes developed by Ratkovic (2014) that balances non-dichotomous variables such as ethnic attachment, which we match on over 80 relevant individual and group-level variables, including wealth, ethnicity, district and partisanship. This allows us to compare individuals that are equivalent in all those respects and yet differ in their level of ethnic attachment. The magnitude of the effect is similar across modeling strategies.

\section{Ethnic identity and regionalism}

\subsection{Regionalism as a deviation from a centralist status quo}

Gellner (1983, p. 1) defines nationalism as "a political principle which holds that the political and the national unit should be congruent". When such congruence is amiss, a secessionist movement aimed at remedying the situation might emerge. Along the same lines, Hechter (2000, p. 9) argues that nationalism is different from regionalism, "which entails collective action designed to change the existing balance of rights and resources between the center and the periphery". If such demands do not include sovereignty, "then [regionalism] fails to qualify as a type of nationalism".

We define regionalism as a principle which holds that the differences between the political and the ethnic unit should be reduced, for instance through the devolution of power from the central government towards ethnically-defined regional governments (regional decentralization). A regionalist is an individual or group who holds that principle. Consider

\footnotetext{
${ }^{6}$ The $66 \%$ is not statistically different from 0 because the number of secessionists in Uganda is low regardless of the level ethnic attachment.

${ }^{7}$ See Sambanis and Milanovic (2011) for a concise literature review.
} 
the following definitions to illustrate the differences between autonomy, federation and secession, all of which we consider to be forms of regionalism. An autonomist is an individual who desires some limited degree of regional decentralization. A federalist desires more: a federal state. Finally, regionalist individuals or groups who believe that regional governments should be independent countries are rightly called secessionists, consistent with Gellner's definition of nationalism which implies a will to secede from the larger political unit. In sum, we can characterize phenomena generally seen as dichotomous - tribalism vs. nationalism, regionalism vs. centralism - in an ordinal or continuous manner that allows for finer theory and measurement.

\subsection{Group and individual demands for regionalism}

It has long been established, most notably by Horowitz (1985, p. 233), that large differences in regional levels of wealth combined with salient identities among politically excluded ethnic groups is conducive to regionalist conflict. He rightly notes that interest in separatism can come from groups in both backward and advanced regions. Groups in richer regions would prefer to keep their wealth rather than subsidize poorer regions (such as with Sikh Punjabis in India in the 1980s or Catalonia in Spain), while the feeling or marginalization can lead individuals from poorer regions to demand more autonomy (as in North-East India, South Sudan and Sri Lanka). In contrast - although Horowitz does not make this logic explicitgroups that have average levels of wealth feel less marginalized than those in the poorest regions, and are unlikely to increase their income under a regional government because they are the least affected by regional redistribution. Thus, we should expect a U-shaped relationship between group/regional wealth and demands for regionalism. ${ }^{8}$

And yet we also know ethnic groups are intrinsically diverse. We argue that within-group variation in attachment to one's identity affects individual preferences for regionalism. "If the demand for sovereignty [or regionalism] is a function of its net benefits, then it should vary between individuals in a given nation [or region]" (Hechter, 2000, p. 122-3). While the explanation intuitively applies to material benefits, individuals that strongly identify with their ethnicity may also derive psychological or non-material benefits from regional decentralization.

\footnotetext{
${ }^{8}$ Horowitz also distinguishes between backward and advanced groups, such that there are advanced groups in backward regions and backward groups in advanced regions. However, in both cases he correctly notes a general lack of interest in secession or separatism due to a more complex calculation of costs and benefits.
} 
There is now a large literature on what explains both the origins of ethnic identity as well as individual-level variation in ethnic attachment. As regards the former, research shows that ethnic diversity can be explained as a result of tropical geography, state history, genetic diversity, land diversity, modern state strength and colonial rule (Ahlerup and Olsson, 2012; Ashraf and Galor, 2013; Bleaney and Dimico, 2016; Green, 2013; Michalopoulos, 2012; Wimmer, 2015). This literature helps to explain why Uganda is so ethnically diverse, with its proximity to the equator, a history of slavery, and short state history. As regards the latter, the broader literature on nationalism has suggested that ethnic identities only yield to modern national identities through broader processes of modernization, industrialization and urbanization (Gellner, 1983; Weber, 1976). More recently, Green (2013) and Robinson (2014) have similarly argued that gender (male), urban residence, formal employment and higher levels of education are all positively correlated with national over ethnic identification. Finally, Eifert et al. (2010) suggest that competitive elections cause ethnic identities to become more salient relative to other identities. ${ }^{9}$

We can posit three ways in which within-group variation in demands for regionalism should exist. First and foremost, the strength of one's ethnic identity should correlate positively with the demands for regionalism in a context where regions are created along ethnic lines. There is now a substantial body of literature suggesting a robust relationship between identity and support for regional devolution or secession in Belgium (Dodeigne et al., 2014), Russia (Hagendoorn et al., 2008) and Spain (Boylan, 2015; Muñoz and Tormos, 2015). ${ }^{10}$

The reason for this congruence between ethnic identity and attachment to regionalism lies in the dominance of nationalism and ethno-national identity as the pre-eminent modern form of state legitimacy (Mann, 2005; Wimmer, 2002). In the pre-modern past, rulers were legitimized according to class and society was often divided horizontally, such that class trumped ethnicity. Instead, states in the modern era are often legitimized by ethnic or national identity and society has thus become more vertically stratified, such that ethnicity or nationally often sometimes trumps class. ${ }^{11}$ According to this logic, individuals who identify more with the nation would prefer a centralist arrangement, while those who identify more with their sub-national ethnic group would prefer some regional decentralization. ${ }^{12}$

\footnotetext{
${ }^{9}$ We examine the empirical correlates of individual-level ethnic attachment in section 5 .

${ }^{10}$ In all of these cases the data was collected after regional governments had already been established. Our case study allows us to examine the same relationship without any such government yet.

${ }^{11}$ Note that this view is not homogeneous within the social sciences. Hechter (2013), for instance, notes the ways in which alien or non-native rulers can become legitimate through effective and fair governance.

${ }^{12} \mathrm{An}$ alternative means to the same end is posited by Alesina and Spolaore (2003), who suggest that the size and borders of states are drawn by trading off economies of scale and heterogeneous preferences.
} 
A second potential source of variation in demands for regionalism depends on the relative size of each ethnic group in the region. Indeed, unless a region is ethnically homogeneous or evenly fragmented, the largest group in the region stands to benefit the most from regional decentralization by becoming the majority or plurality. Smaller groups in the region might very well be indifferent between a central government and a new regional government that they cannot control either. Therefore, the effect of ethnic attachment might depend on whether the group is a majority or a minority in the region.

Third and finally, within-group variation can result from a comparison of material benefits under different levels of regional decentralization. We know richer regions and ethnic groups tend to prefer fiscal federalism in order to keep a larger share of the revenue they generate (Sambanis and Milanovic, 2011; Alesina and Spolaore, 2003) even if these demands might generally fall short of secessionism (Horowitz, 1985). At the individual level, richer individuals within a region might prefer more regionalism hoping to (i) retain a larger share of private and public revenues in the region and (ii) enjoy the political spoils, such as the newly created jobs of an expanded bureaucracy (Breton, 1964). Thus we would expect to see a positive relationship between individual wealth and preference for regionalism.

\section{Context}

Uganda is very ethnically diverse, with 65 ethnic groups recognized by the constitution. We use original data from a nationally representative survey conducted in Uganda in the summer of 2012. Uganda is a country that extends $236,040 \mathrm{~km}^{2}$ and is populated by around 35 million inhabitants. Ethnicity usually coincides with an individual's first language in Uganda but there is religious diversity within ethnic groups. Figure 1 shows that the West, the East and the North contain multiple ethnic homelands. Only the Central region, the homeland of the Buganda Kingdom, is ethnically homogeneous, albeit with numerous migrants from other parts of the country.

While recent decades have been peaceful, Uganda's past has been rather tortuous. In the late 19th century, Britain colonized the area surrounding the kingdom of Buganda, which lent both its name and capital city to the colony as a whole. However, the country eventually encompassed four other kingdoms in the South and South-West as well as stateless societies in the East and North. In the run-up to independence, Buganda kingdom leaders fought hard for more autonomous rule, even threatening to secede from the country in 1960. As a result Britain left Uganda upon independence in 1962 with a strange mix of a federal government for the kingdom of Buganda, a semi-federal system for the country's other four traditional 
Figure 1: Main ethnic groups in Uganda (2001)

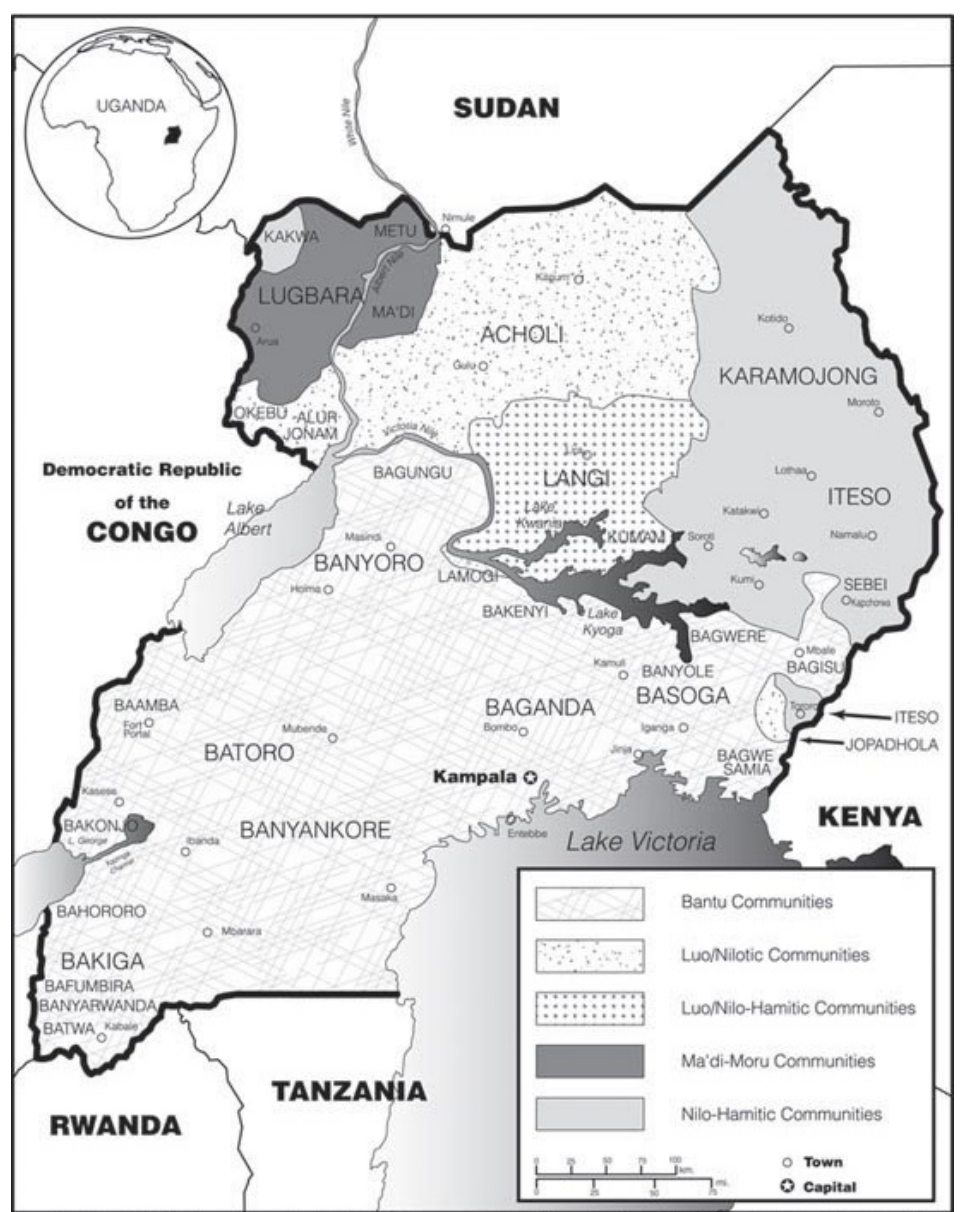

Note: The map shows the ethnic and linguistic diversity of Uganda. Ethnic groups appear in capital letters. Source: Minority Rights Group International (2001).

kingdoms and a unitary system for the rest of the country. After only four years Prime Minister Milton Obote staged a coup d'etat and deposed the then President, the Kabaka (king) of Buganda, leading to another futile declaration of independence by the kingdom's government and the eventual exile of the Kabaka to Britain. Obote then introduced a unitary system of government under a new constitution that abolished kingdoms as political entities. The next two decades proved to be incredibly disastrous for the country as a whole due to Idi Amin's misrule and a prolonged civil war. At no point since then has there been an organized effort for secessionism among the Baganda or any other group. ${ }^{13}$

\footnotetext{
${ }^{13}$ The lone exception was a brief attempt at secession among the Bakonjo and Baamba in western Uganda in the early 1960s.
} 
Since the 1990s, the country has undergone a radical program of local decentralization under President Yoweri Museveni, a Munyankole (West) and head of the National Resistance Movement (NRM), which took power by force in 1986. While prominent figures in development circles such as Mahmood Mamdani first praised the program, it has been criticized in the last decade as a covert form of patrimonialism or generally as a scheme that grants political spoils but very little fiscal autonomy to the districts, the number of which has increased from 39 to 112 over the past two decades (Grossman and Lewis, 2014). The main independent newspaper, the Daily Monitor, has echoed the criticism of "district inflation" by local politicians and MPs, ${ }^{14}$ as well as by opposition members and donors (Green, 2010).

The rapid increase in the number of districts in Uganda - which now has more highest-tier local governmental units than any other country in the world-has resulted in an increased interest in a regional tier of government. Indeed, in 2005 the Ugandan Parliament passed a constitutional amendment that allowed districts to cooperate to form new regional governments. Despite no explicit mention of ethnicity in the amendment, the identified regional tiers - notably Buganda, Bunyoro, Busoga, Acholi and Lango - are all traditional ethnic homelands, which suggests that a future regional tier of government would divide up the country along ethnic lines (Government of Uganda, 2005). These regions are essentially the same as the highest-level local government units that were created upon independence in Uganda's 1962 Constitution, which were identified as kingdoms in southern and western Uganda and districts elsewhere. However, despite a subsequent Regional Governments Bill in 2009 which sought to provide for the establishment of regional governments (cf. Goodfellow, 2014), the tier has yet to be created and thus Uganda continues to fit the modal African country where centralism is the status quo.

Whatever the shortcomings of local decentralization may be, Uganda's centralism under Museveni has thus far prevented ethnicity from playing an explicit institutional role. The reason lies in part in the NRM's strategy to restore former kingdoms merely as cultural institutions with no political power. ${ }^{15}$ Over the past two decades various groups around the country have organized themselves non-violently to receive district status with the prospect of receiving more transfers from the central government. This has led to political rather than ethnic competition since ethnic and district borders need not coincide.

\footnotetext{
${ }^{14}$ Two vignettes in the online appendix allude to the financial under-provision that districts suffer (Figure 7) and to the clientelistic use of new districts (Figure 8).

${ }^{15}$ The only kingdom not restored was Ankole, which happens to be the home territory for President Museveni. The ostensible reason given for not restoring Ankole was its local unpopularity; however, some have speculated that another reason was that the Omugabe (king) of Ankole would be, if restored to his position, politically superior to Museveni himself according to traditional norms.
} 
Table 1: Poverty and Development by Region, 2012-2013

\begin{tabular}{lcc}
\hline \hline Region & $\begin{array}{c}\text { Monthly Consumption Expenditure } \\
\text { per capita (2005USH) }\end{array}$ & $\begin{array}{c}\text { Poverty Headcount } \\
\text { (in \%) }\end{array}$ \\
\hline Central & 73,060 & 4.7 \\
East & 35,906 & 24.5 \\
North & 31,140 & 43.7 \\
West & 53,657 & 8.7 \\
\hline
\end{tabular}

Note: Poverty headcount is defined as the "percentage of people living in households where consumption is below the poverty line." Source: UBOS (2014, pp. 28, 30).

In spite of the relative peace, mostly disturbed by the Lord's Resistance Army, sharp regional economic differences remain (Table 1). Buganda, or the Central region, is still the richest region. Conventional wisdom of Ugandan politics suggests that support for regionalism - and specifically federalism - should be very high in Buganda, where the movement for the restoration of a federal government has been dubbed "federo". The North was peripheral during colonialism, but Northern leaders in power from 1966 until 1986, mostly through military means, favored their home region. However, recurrent conflict led to zero or negative country growth and the North remains the poorest region today. Returning to the logic of group demands for regionalism, we should observe high support for regionalism in the poorest region (North) as well as the richest one (Buganda). The West is a fast growing region with a developed infrastructure and tourism industry. Since poverty is below average, a fiscal federalism rationale implies many Westerners might support federalism, like the Baganda. However, they have in part enjoyed this growth because of the discretionary spending of a centralized government that mostly hails from the West. Because they are the political core, they should be the least supportive of regionalism among the four regions.

\section{Data}

Surveys were conducted by over 80 Ugandan enumerators grouped in 9 teams $(n=3,484)$. Field work and data collection were designed and supervised by six graduate students and three professors in the summer of 2012. Only the Ugandan nationals conducted surveys to avoid any "white man" interviewer effect (Cilliers et al., 2012). The random sample includes 42 of the 112 districts, with around 10 districts per region to achieve regional balance. This resulted in a sample of individuals from over 20 ethnic groups, 19 of them with over 30 respondents each. Qualitatively, the research was also informed by interviews conducted with former presidential candidate Betty Kamya (Uganda Federal Alliance), former Chief Justice 
Benjamin Odoki, USAID expert in decentralization Robert Kalemba, Professor Frederik Ssempebwa, and two focus groups. The survey asks the following questions to determine preferences for degree of regionalism and ethnic attachment:

I will now present to you several ways in which Uganda could be politically organized. Do not tell me which one is possible or likely. Instead, tell me which one you prefer the most:

1. A Uganda where most decisions are taken by the national government. That is how Uganda is currently organized.

2. A Uganda where the regions have administrative power but most decisions are still taken by the national government.

3. A Uganda where the regions have political power. This could be a federal Uganda where some decisions are taken by the national government and others by regional governments.

4. A Uganda where the regions have political power and where the national government allows regions the option of full autonomy or secession from Uganda.

Let us suppose that you had to choose between being a Ugandan and being [ethnicity of the respondent inserted here, e.g. Ateso]. ${ }^{16}$ Which of the following statements best expresses your feelings?

\section{I feel only Ugandan}

2. I feel more Ugandan than [respondent's ethnicity]

3. I feel equally Ugandan and [respondent's ethnicity]

4. I feel more [respondent's ethnicity] than Ugandan

5. I feel only [respondent's ethnicity]

The ethnic attachment question was asked within the first 15 minutes of the survey. The question on preferences for regionalism, on the other hand, was asked towards the end of the survey. This ordering prevents the latter question from affecting the former. ${ }^{17}$ We also wanted to ensure that the question on regionalism was meaningful to survey respondents given that neither regions nor sub-regions have existed as administrative units since they

\footnotetext{
${ }^{16}$ We were able to insert the ethnicity of the respondent from a previous answer thanks to using around 80 tablet computers, one for each Ugandan enumerator. This question is identical to one asked in Afrobarometer surveys; elsewhere it has become known as the "Moreno question" after the Spanish political scientist who pioneered its use in Scotland and Catalonia.

${ }^{17}$ Most of the survey took place between the two questions and was unrelated to ethnicity.
} 
were abolished in $1966 .{ }^{18}$ To that end, we conducted two focus groups with Ugandans from all four regions. ${ }^{19}$ Participants in the focus groups stated that the four regions are common knowledge and so is the distinction between region and district. However, some members in the focus group suggested respondents might be thinking of more cultural concepts such as sub-region (Figure 3) or kingdom when asked about regionalism, especially if they come from an area where there is a kingdom. The survey prevents such misunderstanding by asking individuals about their region of origin (Central, East, North, or West) early in the survey.

Qualitative interviews suggested that the word "federalism" would reduce the support for that option everywhere in the country except in the Central region. They indicated that some respondents might switch their response from federalism to regionalism because federalism has historically been associated with Buganda privileges, although this understanding of federalism is changing. Support for federalism should thus be interpreted as a lower bound outside the Central region.

\subsection{Descriptive results}

We begin by showing that there is interesting variation in preferences for regionalism by aggregating the data by region (Figure 2) and by subregion (Figure 3). Almost $40 \%$ of individuals in the Central Region and close to $30 \%$ in the Northern region support federalism. $6.8 \%$ of Northerners favor secession while in any of the other regions support is below $3 \%$, consistent with Horowitz's claim that backward regions are more likely to be secessionists. Federalism in the North is supported mainly by members of the Acholi (35\%) and Langi (34\%) ethnic groups, the two largest groups in that region. These rates are equivalent to the Central region, where support for federalism is $30 \%$ overall and $36 \%$ among the Baganda, the ethnic majority in the region. Also consistent with section 2, very few support federalism in the East and West $(<15 \%)$. For instance, the support is only $12 \%$ among the Banyankole, Museveni's ethnic group. However, even in those two regions $70 \%$ of the population want some form of regional government - most want limited autonomy — which presently does not exist. The map is consistent with our logic that both the most and the least developed regions express, on average, higher preference for regionalism.

\footnotetext{
${ }^{18} \mathrm{Also}, 44 \%$ of our sample had not finished primary school, in line with the national average. Reassuringly, decentralization preferences by region are almost identical between the $44 \%$ that did not finish primary and the $56 \%$ that did.

${ }^{19}$ We conducted two focus groups of six members each in July of 2012. Discussions lasted roughly two hours in each case. We instructed the organizer to recruit three males and three females in each group from different ethnic groups that did not know each other beforehand. The focus groups were ethnically mixed to foster engaged discussions.
} 
Figure 2: Regionalist preferences by region
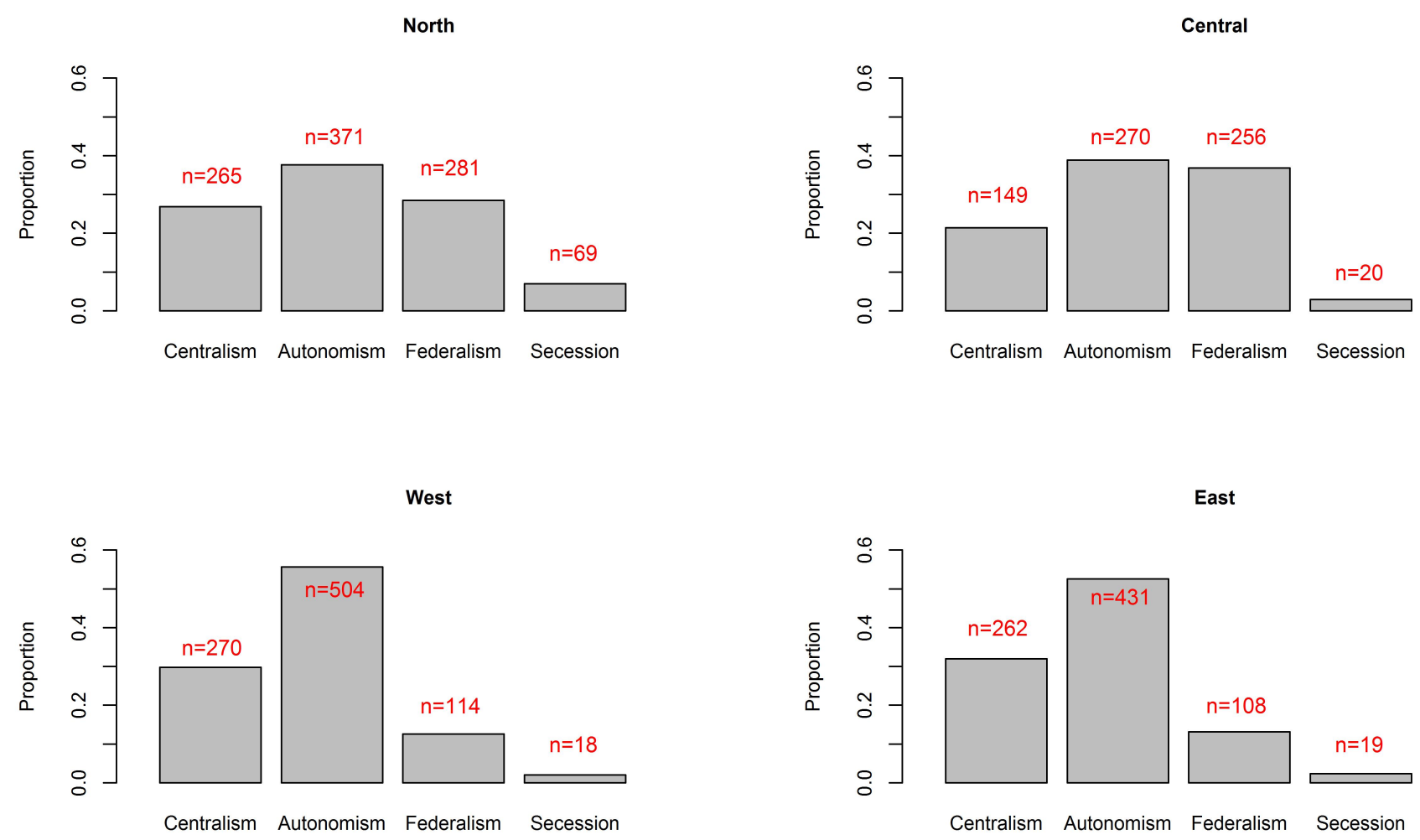

Note: The bar plots shows the distribution of responses for our dependent variable (regionalist preferences) across the four Ugandan regions.

The focus groups showed patterns roughly consistent with the bar graphs. No participant was secessionist, most desired some level of autonomy or federalism. Many argued that regional governments could be a positive check on Museveni's authority and improve accountability. Not everyone agreed, however. While a participant from the Central region was quite vocal in his defense of federalism, a Westerner with links to Museveni's NRM was a staunch centralist, arguing that thanks to centralism ethnic conflict had mostly disappeared in Uganda. While there is little prospect of regional decentralization in the near future, some citizens had strong positions on the issue.

\section{Results}

To understand these descriptive patterns, we begin by showing that group differences in ethnic attachment and wealth are correlated with preferences for regionalism. Next, we use multilevel models test more rigorously whether these group-level correlations are mostly the 
Figure 3: Regionalism and ethnic attachment by sub-region

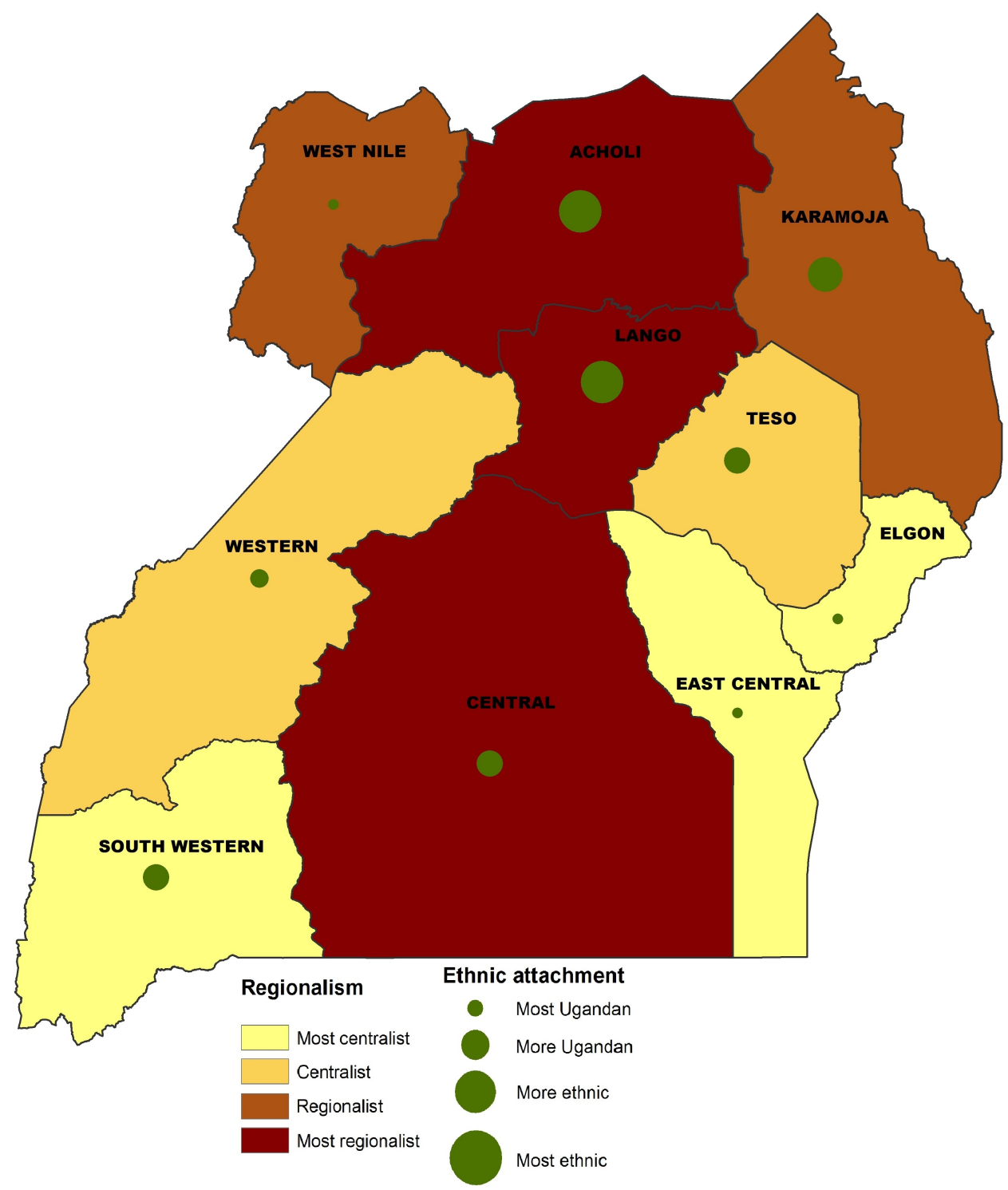

Note: The map presents average levels of regionalism and ethnic attachment plotted by subregion and divided in quartiles.

result of group-level factors or whether there is meaningful individual-level variation even when we take ethnic group and district characteristics into account. Finally, we examine whether higher individual ethnic attachment causes an increased preference for regionalism using several fixed effects specifications and a new matching method. 


\subsection{Group-level correlations}

The first step is to determine whether there is a correlation between group-level ethnic attachment and group regionalism, as identity-based explanations would predict, and between group-level income and group regionalism, as interest-based explanations would predict. Grouping the data by district or ethnicity results in fewer than 50 observations and we do not claim any causal claims. However, the correlations we present in Figures 4 and 5 are novel and interesting in themselves. ${ }^{20}$

The two plots convey two interesting points. First, when ethnic group is the unit of analysis, regionalism is linear in ethnic attachment but U-shaped in income. The U-shaped relationship is mostly driven by the Acholi and the Langi on the low income side, and by the Baganda on the high income side. Ethnic attachment, wealth and wealth squared alone explain $39 \%$ of the variation in preferences for regionalism (adjusted $R^{2}=0.27$ ). Second, the U-shaped pattern holds when we analyze the data by district. As expected, preference for regionalism as a function of ethnic attachment remains linear. ${ }^{21}$ Ethnic attachment, wealth and wealth squared alone explain $20 \%$ of the variation in preferences for regionalism (adjusted $R^{2}=0.13$ ). This exercise quantifies insights uncovered in interviews and, most importantly, provides evidence for Horowitz's (1985) theory of regionalism (section 2.2).

\subsection{Multilevel models}

The plots above are visually interesting but only present raw correlations. Multi-level models allow us to disentangle more rigorously between two possibilities. First, it could be that the differences we observe between groups are simply a result of individual-level factors. In other words, group-level factors would be irrelevant once we take into account differences between individuals in ethnic attachment, wealth and other covariates. On the other hand, it could be that group - rather than individual - ethnic attachment and wealth are the key to explain preferences for regionalism. In that case, some of the variation we observe in the plots would indeed be at the group level. We consider two levels in our models: level 1 consists of individuals and level 2 of groups, conceived as either districts (models 1 and 2 of Table 2) or (models 3 and 4). We estimate the following linear equations by maximum likelihood:

$$
Y_{i j}^{*}=\beta_{0 j}+\beta_{1 j} E_{i j}+\beta_{2} W_{i j}+\delta X_{i j}+\epsilon_{i j}
$$

\footnotetext{
${ }^{20}$ Tables 5 and 6 in the online appendix present the corresponding statistical results.

${ }^{21}$ The linear and quadratic fits in the right scatterplot of Figure 5 do not include Mubende, an extreme outlier likely due to small sample size.
} 
Figure 4: Regionalism by ethnic group
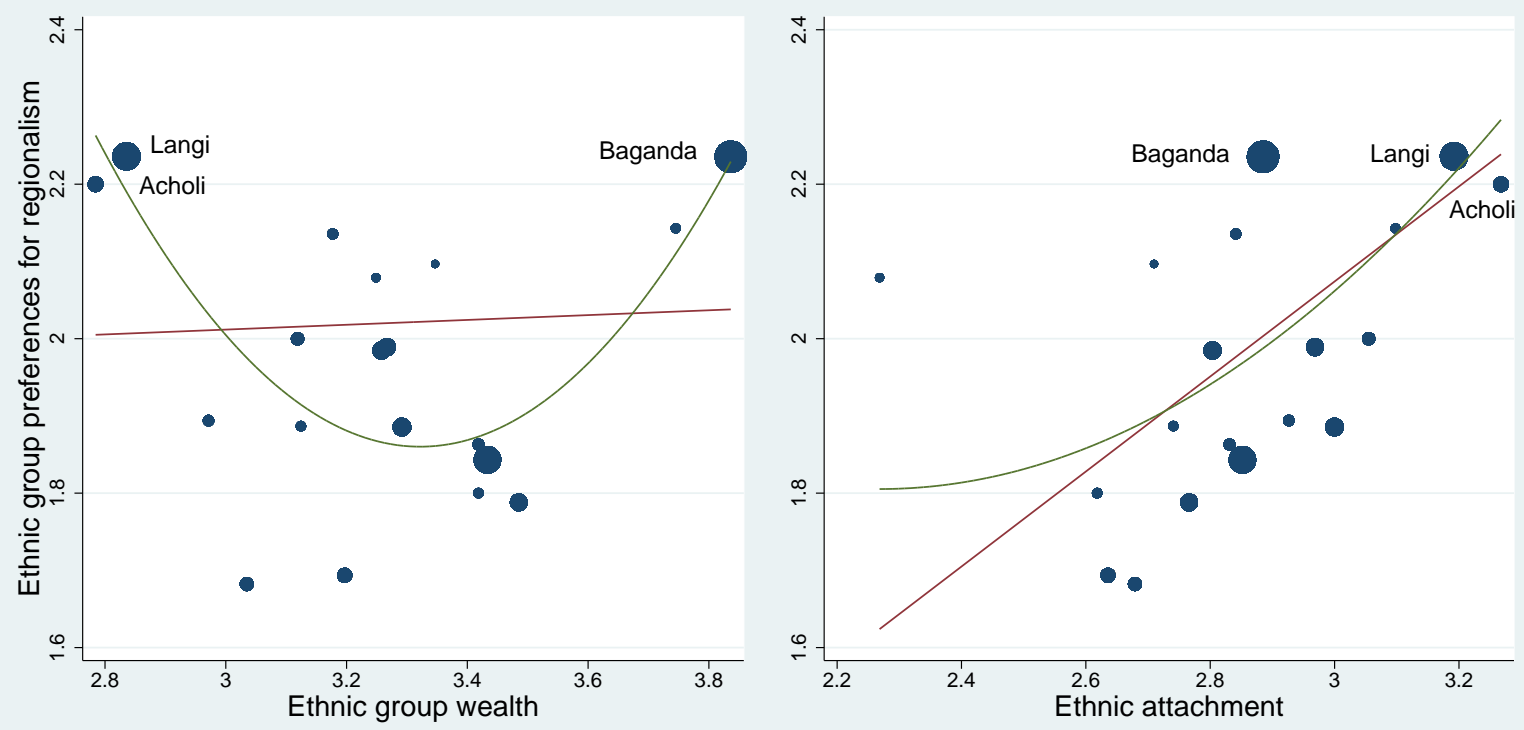

Figure 5: Regionalism by district
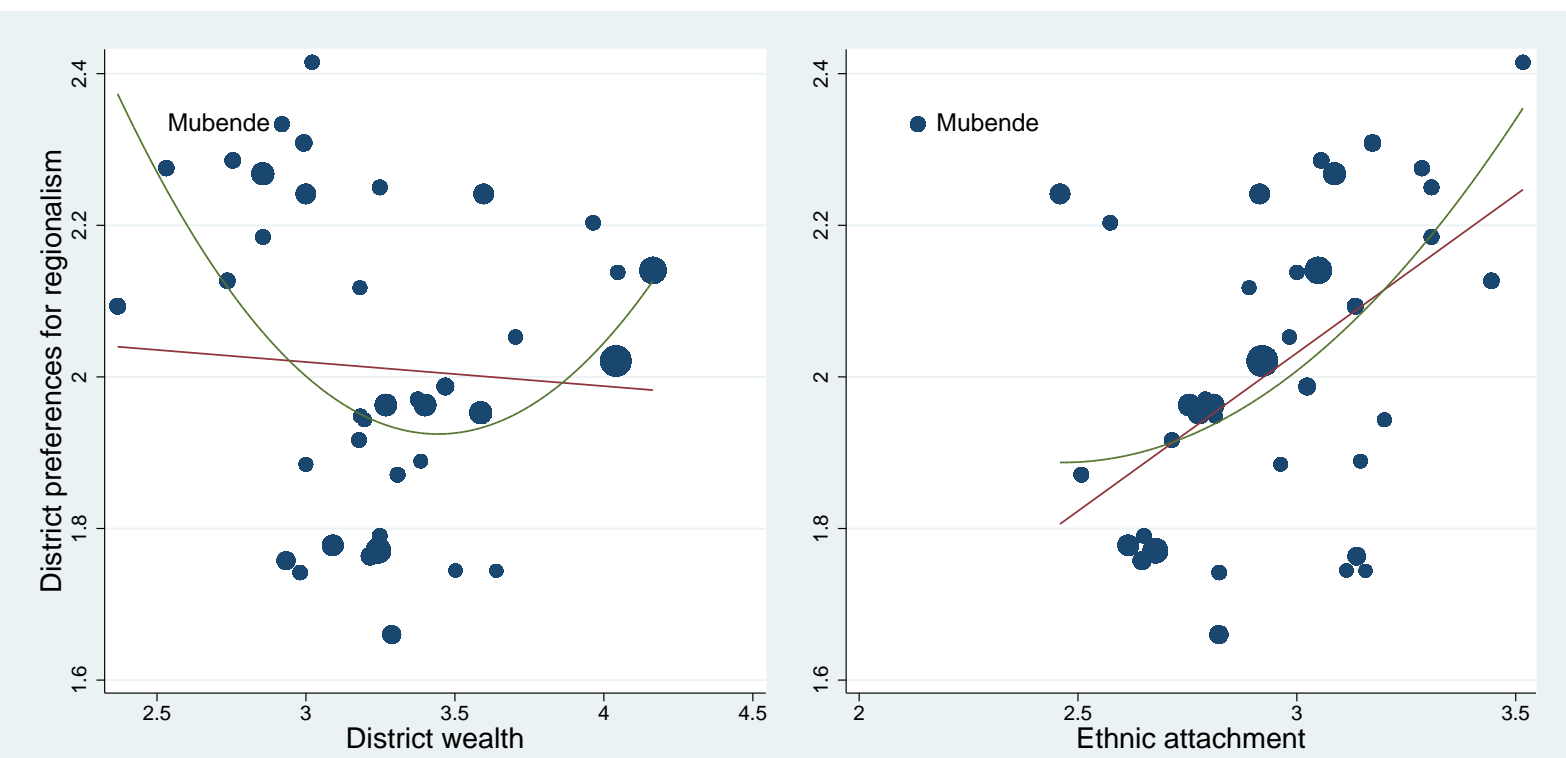

Note: The figures show the average levels of ethnic group wealth and ethnic attachment (Figure 4) and the average levels of district wealth and ethnic attachment (Figure 5). The straight line in each graph is a line of best fit between the $\mathrm{X}$ and $\mathrm{Y}$ axis. The curved line squares the variable in the $\mathrm{X}$ axis to allow for the possibility of a U-shaped relationship. The observations or dots vary by size as a function of survey sample size, such that the more populous groups have larger dots.

where $Y^{*}$, the dependent variable, measures preferences for regionalism. ${ }^{22} \beta_{0 j}$ in an intercept that varies by group and hence modeled in the level 2 equation below, $E$ is individual ethnic

\footnotetext{
${ }^{22}$ In section 2.1 we defined regionalism as a deviation from the centralism. We can think of the dependent variable as a latent variable representation of that deviation $\left(Y^{*}\right)$ for which four outcomes are observed.
} 
attachment, $W$ is individual wealth, $X$ is a vector of individual controls listed at the bottom of Table 2, and $\epsilon$ is the level 1 random error. We choose the individual-level controls in part due to the existing literature, which shows that gender, urban residence, and education may affect individual levels of ethnic attachment. We model the group variance as:

$$
\beta_{0 j}=\gamma_{0}+\gamma_{1} E_{j}+\gamma_{2} W_{j}+v_{0 j}
$$

where $\gamma_{0}$ is the overall intercept across groups, $E$ and $W$ are group-level ethnic attachment and wealth (level 2 predictors), and $v$ is the group-level error term.

Models in Table 2 show that group-level random intercepts are significant and hence explain some of the variation in preferences for regionalism. Thus, the group-level correlations we present in Figures 4 and 5 are not simply the result of individual-level factors. However, they play a modest role: only $3-4 \%$ of the variation is explained at the group level, as we know from calculating the intra-class correlation (ICC). Further, group-level ethnic attachment seems to matter when the units of analysis are districts and wealth seems to matter when they are ethnic groups. Hence, we cannot be confident about the exact source of the between-group variation. Finally, the ICC is below the 5\% "rule of thumb" (Barcikowski, 1981) that suggests group-effects are substantively relevant-over $95 \%$ of the variation is not explained at the group-level. Individual-level ethnic attachment and wealth are significant and identical in size across models. We find no evidence for a non-linear effect of wealth: the group-level U-shape relationship in Figures 4 and 5 does not seems to apply at the individual level. We examine individual-level results in more detail in the remainder of the section. ${ }^{23}$

\subsection{Fixed effects models}

We move to fixed effects models to focus exclusively on within-group variation and determine whether the positive effect of ethnic attachment we observe is causal. Unlike multilevel models, fixed effects models "perfectly capture any clustering by subgroups that may exist in the data, since the dummy variables 'absorb' the unique variation among the subgroups" (Steenbergen and Jones, 2002, p. 220). We use the following estimation equation for the

Hence, we have $Y_{i} \in\{1,2,3,4\}$ with each corresponding respectively to centralism, autonomism, federalism and secessionism. Each individual chooses the institutional design closest to his ideal point $Y_{i}^{*}$.

${ }^{23}$ Results are quantitatively almost identical for all coefficients of interests whether we use survey weights or not and whether we use restricted MLE or simple MLE. Steenbergen and Jones (2002, p. 226) suggest restricted MLE to reduce bias in models with few level 2 observations, but results do not change: the random intercepts standard deviation changes from .023 to .024 and the individual-level ethnic attachment coefficient from .057 to .059. In the paper we present the results with simple MLE to be able to include survey weights and clustered standard errors at the district level in the model. 
Table 2: Multilevel models of regionalist preferences grouping data by district and ethnicity

\begin{tabular}{lcccc}
\hline \hline & $(1)$ & $(2)$ & $(3)$ & $(4)$ \\
& Districts & Districts & Ethnic groups & Ethnic groups \\
\hline Fixed effects equation & & & & \\
$\quad$ Individual characteristics (level 1) & & & & \\
Ethnic attachment & $0.06^{* *}$ & $0.06^{* *}$ & $0.06^{* *}$ & $0.06^{* *}$ \\
& $(0.02)$ & $(0.02)$ & $(0.02)$ & $(0.02)$ \\
Wealth index & $0.07^{* *}$ & $0.07^{* *}$ & $0.07^{* *}$ & $0.07^{* *}$ \\
& $(0.02)$ & $(0.02)$ & $(0.02)$ & $(0.02)$ \\
Constant & $1.56^{* *}$ & $1.56^{* *}$ & $1.46^{* *}$ & $1.46^{* *}$ \\
& $(0.13)$ & $(0.13)$ & $(0.13)$ & $(0.13)$ \\
\hline Random effects equation & & & & \\
Variance components $(l e v e l ~ 2)$ & & & & $0.03^{* *}$ \\
Group-level random intercepts $\left(\sigma_{\alpha 1}\right)$ & $0.16^{* *}$ & 0.00 & $0.13^{* *}$ & $(0.02)$ \\
& $(0.02)$ & $(0.00)$ & $(0.02)$ & 0.07 \\
Group-level ethnic attachment $\left(\sigma_{\alpha 2}\right)$ & & $0.16^{* *}$ & & $(0.12)$ \\
& & $(0.02)$ & & $0.00^{* *}$ \\
Group-level wealth $\left(\sigma_{\alpha 3}\right)$ & & 0.00 & & $0.00)$ \\
& & $(0.00)$ & & $(0.03)$ \\
Individual-level error $\left(\sigma_{\epsilon}\right)$ & $0.76^{* *}$ & $0.76^{* *}$ & $0.77^{* *}$ & 2960 \\
& $(0.02)$ & $(0.02)$ & $(0.03)$ & -3472.43 \\
\hline Observations & 3074 & 3074 & 2960 & 19 \\
Log. lik. & -3600.13 & -3600.13 & -3472.51 & 0.01 \\
Clusters & 42 & 42 & 19 & \\
Intra-class correlation & 0.04 & 0.04 & 0.03 & \\
\hline \hline
\end{tabular}

Notes: $\dagger p<0.10,{ }^{*} p<0.05,{ }^{* *} p<0.01$. Standard errors are clustered at the level 2 unit of analysis, which is the district in models 1 and 2 and the ethnic group in models 3 and 4 . We include only the 19 ethnic groups with 30 or more individuals in the sample. All models contain the following additional controls: age, male, education, perception of corruption and levels of trust in coethnics, in the governing party and in the local council chairman. Results are quantitatively very similar when we exclude some of the controls, such as the trust battery, that could be inducing post-treatment bias. The intra-class correlation (ICC) is the ratio of standard deviations $(\sigma)$ between group-level parameters, denoted by $\alpha$, and the individual-level residual, denoted by $\epsilon$ : ICC $=\sum_{i=1}^{N} \sigma_{\alpha_{i}} /\left(\sum_{i=1}^{N} \sigma_{\alpha_{i}}+\sigma_{\epsilon}\right)$.

ordered logit model:

$$
Y_{i j k}^{*}=\alpha+\beta E_{i j k}+X_{i j k} \gamma+\delta_{j}+\eta_{k}+\epsilon_{i j k}, \quad \epsilon_{i j k} \sim \operatorname{logistic}(0,1)
$$

where we model the outcome $Y^{*}$ defined in eq. 1 (regionalism) for individual $i$ of ethnic group $j$ and where $k$ stands for region in model 2 and district in models 3 and 4 of Table 3 . We denote ethnic attachment by $E$ and $\beta$ is the main coefficient of interest. $X$ includes the remaining variables of what we term the 'ethnic or identity model', as well as the 'interest 
model' and the other individual level controls listed at the bottom of Table 3 . The ethnic group fixed effects are denoted by $\delta$ and the region or district fixed effects by $\eta .^{24}$

The effect of individual ethnic attachment in Table 3 is significant and almost identical in magnitude whether we do not include fixed effects at all (model 1) or we include region (model 2), district (model 3) or district and ethnicity fixed effects (model 4). ${ }^{25}$ The results imply that most between-group variation is captured individual-level controls and by either district or ethnicity indicators, which is reasonable given ethnic groups in Uganda are very geographically concentrated. ${ }^{26}$ The interest model includes individual wealth, evaluation of services in the respondent's district and the number of days the respondent worked in the last month - since those with stable jobs may prefer less institutional change. Increased wealth is associated with a desire for more regionalism. Because ethnic attachment and the wealth index are both 1 to 5 ordinal variables, we can see that effects are very similar in magnitude without using standardized coefficients. While the effects we observe are consistent across multilevel and fixed effects models, they could still be suffering from omitted variable bias. The next section presents a matching method in order to further alleviate that problem.

\subsection{Matching method}

We use a new matching method for general treatment regimes developed by Ratkovic (2014) that is different from traditional matching techniques, such as propensity score matching. Traditional matching methods force researchers to dichotomize the variable of interest, which is sometimes unfortunate and more often unjustifiable. The method we use can balance ordinal, numerical and categorical variables. We balance ethnic attachment, the ordinal variable of interest $(E)$, on over 80 pre-treatment covariates, including individual variables and district and ethnic group indicators. ${ }^{27}$ To ease computation, we reduce ethnic attachment to

\footnotetext{
${ }^{24}$ In generalized linear models like an ordered logit, $\beta$ might not be consistent if the number of groups $j$ is large and the number of observations $i$ is small. Because of the large sample size $(n>2700)$, including 40 district indicators and 27 group indicators simultaneously should not affect consistency.

${ }^{25}$ Region fixed effects are de facto included in models 3 and 4 since regions are a linear combination of districts.

${ }^{26}$ We ran the models with an interaction between ethnic attachment and ethnic regional majority to ascertain whether the effect of ethnic attachment depended was stronger among the ethnic majority. The effect becomes insignificant as soon as we include some fixed effects (models 2 to 4).

${ }^{27}$ Variables include gender, education, work frequency, wealth, public services received (to proxy for welfare), trust in Ugandans, trust in coethnics, trust in the local council chairman (LC3), trust in the governing party (NRM), perceptions of corruption, residence in a kingdom, and membership in the district's ethnic majority. Some of those covariates may not be "pre-treatment", notably the trust battery. As we mention in several table footnotes in the paper, the effect of ethnic attachment is unaffected by the trust battery - these trust variables are not correlated with ethnic attachment $(\rho<0.05)$.
} 
Table 3: The effect of individual ethnic attachment on preferences for regionalism

\begin{tabular}{lcccc}
\hline \hline & $(1)$ & $(2)$ & $(3)$ & $(4)$ \\
\hline \multirow{2}{*}{ Ethnic identity model } & & & & \\
Ethnic attachment & & & & \\
& $0.16^{* *}$ & $0.16^{* *}$ & $0.15^{* *}$ & $0.15^{* *}$ \\
& $(0.04)$ & $(0.05)$ & $(0.05)$ & $(0.05)$ \\
Regional ethnic majority & $0.40^{*}$ & $0.45^{* *}$ & $0.34^{*}$ & 0.01 \\
& $(0.16)$ & $(0.10)$ & $(0.14)$ & $(0.19)$ \\
Kingdom & 0.20 & $0.39^{* *}$ & $0.51^{* *}$ & $1.33^{*}$ \\
& $(0.19)$ & $(0.15)$ & $(0.19)$ & $(0.64)$ \\
Economic interest model & & & & \\
Wealth index & & & & \\
& $0.12^{*}$ & $0.13^{*}$ & $0.16^{* *}$ & $0.17^{* *}$ \\
Years of education & $(0.06)$ & $(0.07)$ & $(0.05)$ & $(0.05)$ \\
& $-0.01^{\dagger}$ & $-0.01^{\dagger}$ & -0.01 & -0.01 \\
Quality of services & $(0.01)$ & $(0.01)$ & $(0.01)$ & $(0.01)$ \\
& $0.12^{\dagger}$ & $0.10^{*}$ & 0.06 & 0.09 \\
Region FE & $(0.06)$ & $(0.05)$ & $(0.06)$ & $(0.07)$ \\
District FE & & & & \\
Ethnicity FE & No & Yes & Yes & Yes \\
\hline Observations & No & No & Yes & Yes \\
Pseudo $R^{2}$ & No & No & No & Yes \\
\hline \hline * $p<077$ & 2877 & 2877 & 2838 \\
& 0.02 & 0.03 & 0.04 & 0.05 \\
\hline
\end{tabular}

Notes: $\dagger p<0.10,{ }^{*} p<0.05,{ }^{* *} p<0.01$. Standard errors in parentheses and clustered at the district level. All models include survey weights at the regional level. The dependent variable has 4 categories: centralism, regionalism, federalism and secessionism. All models contain the following additional controls: age, male, education, residence in a rural area, perception of corruption and levels of trust in coethnics, in the governing party and in the local council chairman. Results are quantitatively very similar when we exclude some of the controls, such as the trust battery, that could be inducing post-treatment bias.

three categories: (1) feeling only Ugandan or more Ugandan than ethnic ( $n=851)$; (2) equally Ugandan and ethnic $(n=1,922)$; and (3) only ethnic or more ethnic than Ugandan $(n=695)$.

In order to alleviate omitted variable bias, Ratkovic's (2014, p. 1) non-parametric method "adapts the support vector machine classifier to identify [the largest] balanced subset of the 
data." The method has two key properties. First, the joint distribution of the pre-treatment covariates is balanced across the three categories of the treatment. In our sample, Tables 8 and 9 in the online appendix show that descriptive statistics of the full sample are similar to those of the balanced sample. For example, the average years of education for the full sample is 7.03 and for the balanced sample it is 6.86 years. "Within-sample balance" is not and cannot be a property of the method, but the full-sample results in Table 3 and the matching results in Table 4 are more credible as a result. The second property of the method is that it keeps the largest balanced subset of the data, that is, the largest subset of the data that does not predict ethnic attachment. In this case, we keep over $55 \%$ of the observations after matching the data. In experimental language, when we use the full data set the outcome is not conditionally independent of the treatment (ethnic attachment) because it is not randomly assigned. This matching method removes the bias caused by observable confounders so that, for the largest possible subset of the data, the treament is balanced across covariates. ${ }^{28}$ Model 1 in Table 4 (eq. 4) is a simple bivariate ordered logit. Model 2 (eq. 5) includes all covariates used to balance ethnic attachment:

$$
\begin{aligned}
Y_{i}^{*} & =\alpha+\beta T_{i}+\epsilon_{i}, & \epsilon_{i} & \sim \operatorname{logistic}(0,1) \\
Y_{i j k}^{*} & =\beta T_{i j k}+X_{i j k} \gamma+\delta_{j}+\eta_{k}+\epsilon_{i j k}, & \epsilon_{i j k} & \sim \operatorname{logistic}(0,1)
\end{aligned}
$$

Table 4: Ordered matching method

\begin{tabular}{lcc}
\hline \hline & $(1)$ & $(2)$ \\
\hline Ethnic attachment (3 categories) & $\begin{array}{c}0.19^{*} \\
(0.08)\end{array}$ & $0.16^{*}$ \\
& No.07) & Yes \\
District fixed effects & No & Yes \\
Ethnicity fixed effects & 1605 & 1605 \\
\hline Observations &
\end{tabular}

Notes: $\dagger p<0.10, * \overline{\overline{<<0.05, * * p<0.01 . ~ S t a n d a r d ~ e r r o r s ~ i n ~ p a r e n t h e s e s ~ a n d ~}}$ clustered at the district level. The dependent variable has 4 categories: centralism, regionalism, federalism and secessionism. Model 2 includes the following additional controls: age, male, education, perception of corruption and levels of trust in coethnics, in the governing party and in the local council chairman. Results are quantitatively very similar when we exclude some of the controls, such as the trust battery, that could be inducing post-treatment bias.

Because the data is balanced, there is almost no change in the point estimates and standard errors of models 1 and 2. Since log odds coefficients are not intuitive, we provide

\footnotetext{
${ }^{28}$ Using potential outcomes notation, the problem is that $Y_{i}(t) \not \Perp \Perp T_{i} \mid X_{i} \quad \forall t \in T$. The method ensures that for an ordinal variable $T_{i}$, at least with respect to observables, we have that $Y_{i}(t) \Perp T_{i} \mid X_{i} \quad \forall t \in T$.
} 
predicted probabilities for the results below. The four plots present the predicted probabilities of model 1 in Table 4 for each type of respondent with all covariates at their means. The average person that identifies mostly or uniquely as Ugandan supports centralism with a $32 \%$ probability. The probability this same person is a centralist if he identifies mostly or uniquely with his ethnicity is only $25 \%$. The difference of $7 \%$ is equivalent to a $22 \%$ decrease. Thus, high ethnic attachment causes a $22 \%$ decrease in the probability of being a centralist. This difference is statistically and substantively significant. The opposite is true for federalism. Only $17.8 \%$ of those who identify as Ugandans support federalism, while there are $23.3 \%$ of federalists among ethnic identifiers. This $5.5 \%$ difference represents a $22.5 \%$ increase.

Figure 6: Predicted probabilities by degree of regionalism
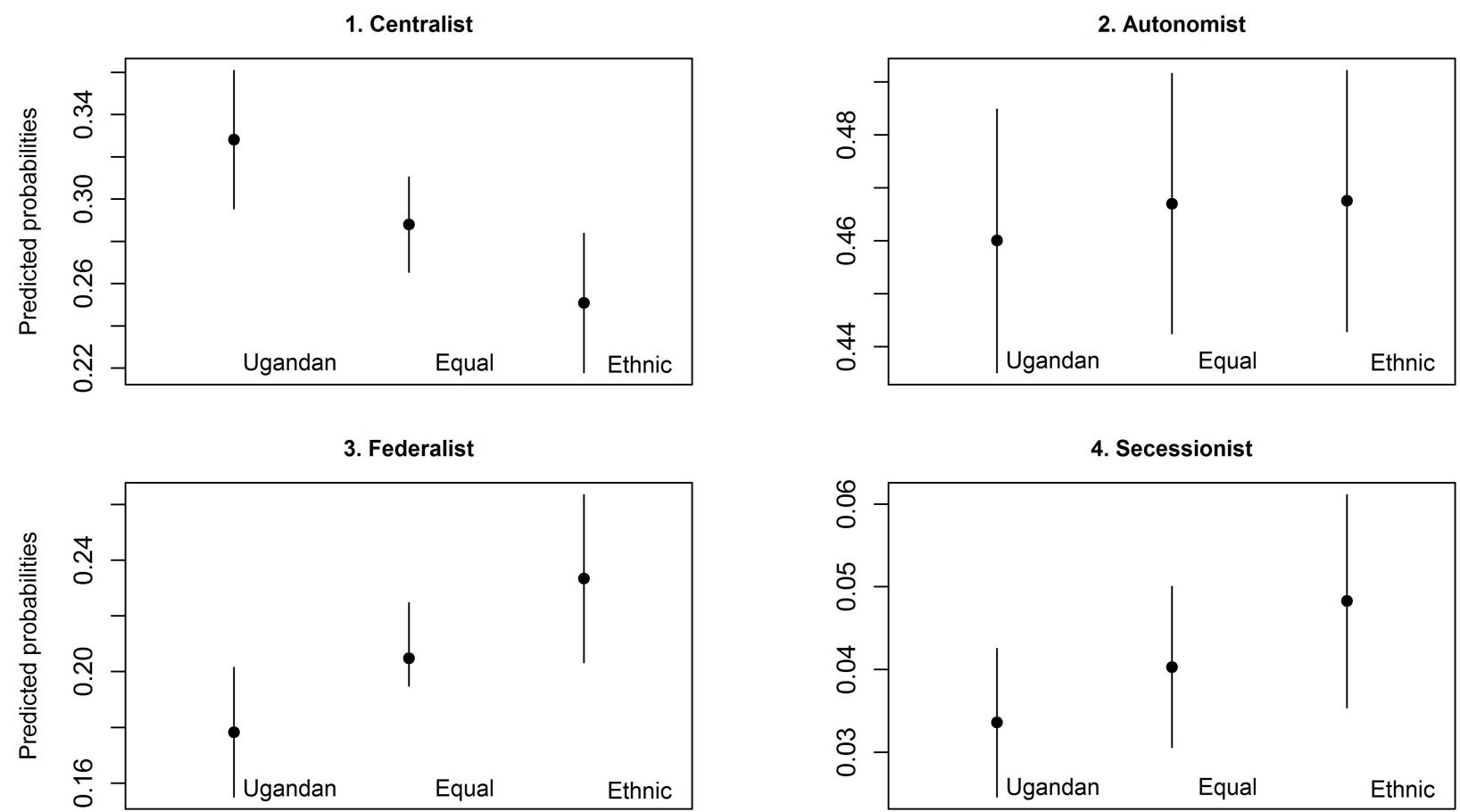

Note: Ethnic: respondent feels more attached to his ethnicity. Equal: respondent feels equally attached to his ethnicity and Uganda. Ugandan: Respondent feels more Ugandan. All point estimates include 95\% confidence intervals. The differences in point estimates for the "centralist" and "federalist" options are statistically significant even if some confidence intervals overap. Also note that, by visual necessity, ranges of Y-axis across plots differ.

The autonomist option is appealing to all those who dislike the centralist status quo but fall short of being federalists. Perhaps because both Ugandan and ethnic identifiers can easily support that option, the predicted percentage of autonomists falls between $46 \%$ and $47 \%$ across categories. Finally, secessionists should be ethnic rather than Ugandan identifiers 
as point estimates suggest, moving from around $3 \%$ to $5 \%$. This $66 \%$ increase is large but not statistically significant because very few people in Uganda are secessionists to begin with, which makes the point estimates imprecise. To recapitulate, our empirical analysis uses several strategies to show that individuals have meaningful preferences about an issue as abstract and yet as essential as the regional organization of their polity.

\section{Conclusion}

Given the pervasiveness of ethnicity for many political economy outcomes, this article focused on the link between ethnic identity and institutional design: how do preferences for regional decentralization vary between ethnic groups and regions? More specifically, does ethnic attachment - how much one identifies with one's ethnicity or national identity — affect one's preferred power-sharing arrangement?

At the group level, we find that preferences for regionalism monotonically increase with an ethnic group's or district's average ethnic attachment, as identity-based explanations would suggest. However, we find that regionalism as a function of ethnicity or district income is U-shaped: both poorer groups, presumably due to marginalization, and richer groups, presumably due to fiscal interests, desire more regional decentralization. While these findings are only correlational, we show for the first time that both logics might be at work within the same country, as argued by Horowitz (1985). Multilevel models show that there is some specific between-group variation but that most is within-group.

At the individual level, we move beyond the observed correlation between ethnic attachment and regionalist preferences by using district and ethnicity fixed effects as well as a new matching method for general treatment regimes. While these two methods rely on different assumptions, they collectively provide strong support for the main hypothesis: identifying with one's ethnicity over one's national identity causes a $22 \%$ decrease in the probability of being a centralist, while it increases the probability of being a federalist by $23 \%$ and a secessionist by $66 \% .^{29}$

Our results have important implications for institutional design, particularly in developing countries that are ethnically diverse. We mark the first effort to examine what type of regional government individuals desire using a nationally representative sample of Ugandans. This gap existed largely because research on institutional design is often prescriptive, from

\footnotetext{
${ }^{29}$ The $66 \%$ is not significantly different from 0 because the number of secessionists in Uganda is low regardless of their level of ethnic attachment.
} 
either a normative or an efficiency viewpoint, and has tended to ignore actual preferences of citizens for whom the institutional design is intended. This is unfortunate since citizens affect the legitimacy and success of a government's regional decentralization program.

We conclude by considering three policy implications that emerge from our research, always with the goal of minimizing the trade-off between increased equality and reduced cultural diversity. The first one is to allow the creation of regional or federal governments for those areas desiring them, which would lead to a system of asymmetrical regionalism or federalism such as existed in Uganda in the early 1960s or in Spain and the United Kingdom today. This solution allows the preservation of cultural and linguistic diversity because decision-makers can adapt policies to a heterogeneous population (Alesina and Spolaore, 2003). However, such a system can induce greater overall regional inequality and political instability in non-advantaged regions, as seen both conceptually (Roeder, 2005; Selassie, 2003) as well as historically in developing countries such as Ethiopia, Sudan and Uganda (Zuber, 2011).

A second option is to reduce extreme regional economic inequality and thus, perhaps, eliminate the ends of the U-shaped relationship between regional wealth and preferences for regionalism. Reducing extreme inequality is positive for political stability and need not reduce diversity. This is perhaps the least costly option in this partial trade-off between equality and diversity. There is now strong evidence that there is a robust positive relationship between horizontal ethnic inequalities and the outbreak of interethnic conflict, including secessionism (Bakke and Wibbels, 2006; Cederman et al., 2011; Deiwiks et al., 2012; Gellner, 1983; Hechter, 1975). In Uganda, the government has designed Equalization Grants from the central government to the districts as a means to channel resources towards underprivileged areas. However, inasmuch as these grants comprise only around $0.5 \%$ of all central government grants to local governments, they have been highly ineffectual (Green, 2015). Ironically, equalization grants have been so small largely because identifying the districts that are most underprivileged and thus deserving of grants is itself a major task in a very poor country (Government of Uganda, 2012, p. 34). ${ }^{30}$ Donors and other organizations, including scholars, could at the very least help governments in poor countries accumulate better data on regional inequalities.

Finally, governments could work to reduce demands for regionalism by actively deemphasizing ethnic attachments. Previous cross-national work has shown that urbanization, formal sector employment and education are all positively correlated with national

\footnotetext{
${ }^{30}$ The serious shortcomings of subnational public finance data in developing countries are evident in current datasets such as the Government Finance Statistics published by the International Monetary Fund.
} 
over ethnic identification within Africa (Green, 2012; Robinson, 2014), while previous work on ethnic conflict in India has suggested that inter-ethnic cooperation can reduce ethnic conflict and thus potentially the salience of ethnic identity as well (Varshney, 2003). Hence, not only could governments prioritize formal job creation and education, but they could encourage more inter-ethnic interaction in institutions where members have equal status (Allport, 1954), particularly among the youth. Makerere University in Uganda, a cradle of East African leaders since its foundation in 1922, has allocated students to their halls of residence randomly and hence without regards to ethnicity since 1970 (Ricart-Huguet and Paluck, 2016). The same policy could be implemented for early adolescents across Ugandan boarding schools, which count among their ranks the future political and economic elite. As with other suggestions, these proposals remain a topic for further research.

\section{References}

Ahlerup, Pelle and Ola Olsson. 2012. "The roots of ethnic diversity." J. Econ. Growth $17(2): 71-102$.

Alesina, Alberto and Enrico Spolaore. 2003. The Size Of Nations. MIT Press.

Allport, G. W. 1954. The nature of prejudice. Cambridge, Massachusetts: Perseus Books.

Amoretti, Ugo M. and Nancy Bermeo. 2004. Federalism and territorial cleavages. Baltimore and London: The Johns Hopkins University Press.

Ashraf, Quamrul and Oded Galor. 2013. "The Out of Africa Hypothesis, Human Genetic Diversity, and Comparative Economic Development." Am. Econ. Rev. 103(1):1-46.

Bakke, Kristin M. and Erik Wibbels. 2006. "Diversity, Disparity, and Civil Conflict in Federal States." World Polit. 59(1):1-50.

Barcikowski, Robert S. 1981. "Statistical Power with Group Mean as the Unit of Analysis." J. Educ. Behav. Stat. 6(3):267-285.

Bleaney, Michael and Arcangelo Dimico. 2016. "State History, Historical Legitimacy and Modern Ethnic Diversity." Eur. J. Polit. Econ. 43:159-170.

Boylan, Brandon M. 2015. "In pursuit of independence: the political economy of Catalonia's secessionist movement." Nations Natl. 21(4):761-785.

Breton, Albert. 1964. "The Economics of Nationalism." J. Polit. Econ. 72(4):376-386.

Burg, Steven L. 2015. "Identity, Grievances, and Popular Mobilization for Independence in Catalonia." Natl. Ethn. Polit. 21(3):289-312. 
Cederman, Lars-Erik, Nils B. Weidmann and Kristian Skrede Gleditsch. 2011. "Horizontal Inequalities and Ethnonationalist Civil War: A Global Comparison." Am. Polit. Sci. Rev. 105(3):478-495.

Cilliers, Jacobus, Oeindrila Dube and Bilal Siddiqi. 2012. "White Man's Burden'? A Field Experiment on Generosity and Foreigner Presence." Work. Pap. .

Deiwiks, Christa, Lars-Erik Cederman and Kristian Skrede Gleditsch. 2012. "Inequality and conflict in federations." J. Peace Res. 49(2):289-304.

Dodeigne, Jérémy, Pierre Gramme, Min Reuchamps and Dave Sinardet. 2014. "Beyond linguistic and party homogeneity: Determinants of Belgian MPs' preferences on federalism and state reform." Party Polit. (September):1-13.

Easterly, William and Ross Levine. 1997. "Africas's Growth Tragedy: Policies and Ethnic Divisions." Q. J. Econ. (November):1203-1250.

Eifert, Benn, Edward Miguel and Daniel N. Posner. 2010. "Political competition and ethnic identification in Africa." Am. J. Pol. Sci. 54(89):494-510.

Fearon, James D. 2003. "Ethnic and Cultural Diversity by Country." J. Econ. Growth $8(2): 195-222$.

Franck, Raphaël and Ilia Rainer. 2012. "Does the Leader's Ethnicity Matter? Ethnic Favoritism, Education, and Health in Sub-Saharan Africa." Am. Polit. Sci. Rev. 106(02):294325.

Gellner, Ernest. 1983. Nations and Nationalism. Ithaca and London: Cornell University Press.

Goodfellow, Tom. 2014. "Legal Manoeuvres and Violence: Law Making, Protest and SemiAuthoritarianism in Uganda." Dev. Change 45(4):753-776.

Government of Uganda. 2005. "Constitution Amendment (No. 2) Act, 2005.".

Government of Uganda. 2012. Review of Local Government Financing. Technical report Local Government Finance Commission Kampala: .

Green, Elliott. 2010. "Patronage, District Creation, and Reform in Uganda." Stud. Comp. Int. Dev. 45(January):83-103.

Green, Elliott. 2012. "Explaining African ethnic diversity." Int. Polit. Sci. Rev. 34(3):235253.

Green, Elliott D. 2013. "Explaining African ethnic diversity." Int. Polit. Sci. Rev. 34(3):235253.

Green, Elliott D. 2015. "Decentralization and Development in Contemporary Uganda." Reg. Fed. Stud. 25(5):491-508. 
Grossman, Guy and Janet I. Lewis. 2014. "Administrative Unit Proliferation." Am. Polit. Sci. Rev. 108(01):196-217.

URL: http://www.journals.cambridge.org/abstract_S0003055413000567

Habyarimana, James, Macartan Humphreys, Daniel N. Posner and Jeremy M. Weinstein. 2007. "Why Does Ethnic Diversity Undermine Public Goods Provision?" Am. Polit. Sci. Rev. 101(4):709-725.

Hagendoorn, Louk, Edwin Poppe and Anca Minescu. 2008. "Support for Separatism in Ethnic Republics of the Russian Federation." Eur. Asia. Stud. 60(3):353-373.

Hechter, Michael. 1974. "The Political Economy of Ethnic Change." Am. J. Sociol. 79(5):1151-1178.

Hechter, Michael. 1975. Internal Colonialism: The Celtic Fringe in British National Development, 1536-1966. London: Routledge.

Hechter, Michael. 2000. Containing Nationalism. Oxford and New York: Oxford University Press.

Hechter, Michael. 2013. Alien Rule. Cambridge: Cambridge University Press.

Horowitz, Donald L. 1985. Ethnic Groups in Conflict. Berkeley and Los Angeles: University of California Press.

Kramon, Eric and Daniel N. Posner. 2016. "Ethnic Favoritism in Education in Kenya." Quart. J. Polit. Sci. (11):1-58.

Lieberman, Evan. 2009. Boundaries of Contagion. Princeton and Oxford: Princeton University Press.

Mann, Michael. 2005. The Dark Side of Democracy: Explaining Ethnic Cleansing. Cambridge: Cambridge University Press.

Michalopoulos, Stelios. 2012. "The Origins of Ethnolinguistic Diversity." Am. Econ. Rev. 102(4):1508-1539.

Minority Rights Group International. 2001. Map of Ethnic Groups and Tribes of Uganda. Technical report.

URL: $h t t p: / / r e l i e f w e b . i n t / m a p / u g a n d a / e t h n o g r a p h i c-u g a n d a$

Muñoz, Jordi and Raül Tormos. 2015. "Economic expectations and support for secession in Catalonia: between causality and rationalization." Eur. Polit. Sci. Rev. 7(2):315-341.

Ratkovic, Marc. 2014. "Balancing within the Margin: Causal Effect Estimation with Support Vector Machines.".

Ricart-Huguet, Joan and Elizabeth Levy Paluck. 2016. "When the Sorting Hat Sorts Randomly: A Natural Experiment on Culture.". 
Robinson, Amanda Lea. 2014. "National Versus Ethnic Identification in Africa: Modernization, Colonial Legacy, and the Origins of Territorial Nationalism." World Polit. 66(4):709746.

Roeder, Philip G. 2005. Power Dividing as an Alternative to Ethnic Power Sharing. In Sustain. Peace Power Democr. after Civ. Wars, ed. Philip G. Roeder and Donald Rothchild. Ithaca, New York: Cornell University Press pp. 51-82.

Sambanis, Nicholas and Branko Milanovic. 2011. "Explaining the demand for sovereignty." World Bank Policy Res. Work. Pap. (November).

Selassie, Alemante G. 2003. "Ethnic federalism: Its promise and pitfalls for Africa." Yale J. Int. Law 28:51-107.

Steenbergen, Marco R. and Bradford S. Jones. 2002. "Modeling Multilevel Data Structures." Am. J. Pol. Sci. 46(1):218-237.

UBOS. 2014. Statistical Abstract. Kampala: Uganda Bureau of Statistics (UBOS).

Varshney, Ashutosh. 2003. Ethnic Conflict and Civic Life: Hindus and Muslims in India. New Haven, CT: Yale University Press.

Weber, Eugene. 1976. Peasants into Frenchmen: The Modernization of Rural France, 18701914. Stanford, CA: Stanford University Press.

Wimmer, Andreas. 2002. Nationalist Exclusion and Ethnic Conflict: Shadows of Modernity. Cambridge: Cambridge University Press.

Wimmer, Andreas. 2015. "Nation Building: A Long-Term Perspective and Global Analysis." Eur. Sociol. Rev. 31(1):30-47.

Wimmer, Andreas, Lars-Erik Cederman and Brian Min. 2009. "Ethnic Politics and Armed Conflict: A Configurational Analysis of a New Global Data Set." Am. Sociol. Rev. 74(2):316-337.

Zuber, Christina Isabel. 2011. "Understanding the Multinational Game: Toward a Theory of Asymmetrical Federalism." Comp. Polit. Stud. 44(5):546-571. 


\section{Online Appendix}

Table 5: Correlation at the ethnic group level between regionalism, ethnic attachment and wealth

\begin{tabular}{lcccc}
\hline \hline & $(1)$ & $(2)$ & $(3)$ & $(4)$ \\
\hline Ethnic attachment, ethnicity average & $0.34^{\dagger}$ & $0.43^{*}$ & & \\
& $(0.17)$ & $(0.15)$ & & \\
Ethnic attachment squared, ethnicity average & & $1.01^{*}$ & & \\
& & $(0.42)$ & & \\
Wealth index, ethnicity average & & 0.01 & -0.07 \\
& & & $(0.16)$ & $(0.13)$ \\
Wealth index squared, ethnicity average & & & & $1.11^{* *}$ \\
& & & & $(0.36)$ \\
Constant & $1.97^{* *}$ & $1.92^{* *}$ & $1.97^{* *}$ & $1.89^{* *}$ \\
& $(0.04)$ & $(0.04)$ & $(0.04)$ & $(0.04)$ \\
\hline Observations & 19 & 19 & 19 & 19 \\
Adjusted $R^{2}$ & 0.15 & 0.34 & -0.06 & 0.30 \\
\hline \hline
\end{tabular}

Notes: $\nmid p<0.10,{ }^{*} p<0.05,{ }^{* *} p<0.01$. Data grouped by ethnicity. The correlations correspond to Figure 4 in the main text. The model is simply $Y_{j}=\beta_{0}+\beta_{1} X_{j}+\beta_{2} X_{j}^{2}+\epsilon_{j}$ where $Y$ is a continuous variable on preferences for regionalism - continuous because we average individual responses - and $X$ stands for ethnic attachment (models 1 and 2) or wealth (models 3 and 4). Analogous to Table 6, the relationship between group ethnic attachment and regionalism can be linearly approximated (model 1), even if the squared term improves fit (model 2). On the other hand, the relationship between group wealth and regionalism is Ushaped (model 4) and cannot be linearly approximated (model 3).

Table 6: Correlation at the district level between regionalism, ethnic attachment and wealth

\begin{tabular}{lcccc}
\hline \hline & $(1)$ & $(2)$ & $(3)$ & $(4)$ \\
\hline Ethnic attachment, district average & & & & \\
& $0.21^{\dagger}$ & $0.19^{\dagger}$ & & \\
Ethnic attachment squared, district average & $(0.11)$ & $(0.10)$ & & \\
& & $0.84^{* *}$ & & \\
Wealth index, district average & $(0.29)$ & & \\
& & & -0.06 & -0.10 \\
Wealth index squared, district average & & & $(0.08)$ & $(0.08)$ \\
& & & & $0.33^{*}$ \\
Constant & $2.01^{* *}$ & $1.95^{* *}$ & $2.02^{* *}$ & $1.97^{* *}$ \\
& $(0.03)$ & $(0.04)$ & $(0.03)$ & $(0.04)$ \\
\hline Observations & 39 & 39 & 39 & 39 \\
Adjusted $R^{2}$ & 0.06 & 0.22 & -0.01 & 0.11 \\
\hline \hline
\end{tabular}

Notes: $\nmid p<0.10,{ }^{*} p<0.05,{ }^{* *} p<0.01$. Data grouped by district. The correlations correspond to Figure 5 in the main text. The model is simply $Y_{j}=\beta_{0}+\beta_{1} X_{j}+\beta_{2} X_{j}^{2}+\epsilon_{j}$ where $Y$ is a continuous variable on preferences for regionalism - continuous because we average individual responses - and $X$ stands for ethnic attachment (models 1 and 2) or wealth (models 3 and 4). Analogous to Table 5, the relationship between group ethnic attachment and regionalism can be linearly approximated (model 1), even if the squared term improves fit (model 2). On the other hand, the relationship between group wealth and regionalism is Ushaped (model 4) and cannot be linearly approximated (model 3). 
Table 7: Correlates of ethnic attachment

\begin{tabular}{|c|c|c|c|c|}
\hline & $(1)$ & $(2)$ & $(3)$ & (4) \\
\hline Kingdom & $\begin{array}{c}-0.17^{\dagger} \\
(0.09)\end{array}$ & & & \\
\hline Acholi & & $\begin{array}{l}0.47^{* *} \\
(0.08)\end{array}$ & & \\
\hline East Central & & $\begin{array}{l}-0.12 \\
(0.09)\end{array}$ & & \\
\hline Elgon & & $\begin{array}{l}-0.18^{*} \\
(0.08)\end{array}$ & & \\
\hline Karamoja & & $\begin{array}{c}0.16^{\dagger} \\
(0.08)\end{array}$ & & \\
\hline Lango & & $\begin{array}{l}0.35^{* *} \\
(0.10)\end{array}$ & & \\
\hline South Western & & $\begin{array}{c}0.13 \\
(0.11)\end{array}$ & & \\
\hline Teso & & $\begin{array}{c}0.11 \\
(0.20)\end{array}$ & & \\
\hline West Nile & & $\begin{array}{l}-0.14 \\
(0.11)\end{array}$ & & \\
\hline Western & & $\begin{array}{l}-0.01 \\
(0.10)\end{array}$ & & \\
\hline Age & & & $\begin{array}{c}0.00 \\
(0.00)\end{array}$ & $\begin{array}{c}0.00 \\
(0.00)\end{array}$ \\
\hline Male & & & $\begin{array}{l}-0.04 \\
(0.04)\end{array}$ & $\begin{array}{l}-0.03 \\
(0.04)\end{array}$ \\
\hline Years of education & & & $\begin{array}{l}-0.01 \\
(0.00)\end{array}$ & $\begin{array}{l}-0.01^{\dagger} \\
(0.01)\end{array}$ \\
\hline Wealth index & & & $\begin{array}{l}0.06^{\dagger} \\
(0.03)\end{array}$ & $\begin{array}{l}0.08^{*} \\
(0.04)\end{array}$ \\
\hline District ethnic majority & & & $\begin{array}{l}0.25^{* *} \\
(0.05)\end{array}$ & $\begin{array}{c}0.10^{\dagger} \\
(0.06)\end{array}$ \\
\hline Rural area & & & $\begin{array}{c}0.05 \\
(0.06)\end{array}$ & $\begin{array}{c}0.11 \\
(0.07)\end{array}$ \\
\hline Constant & $\begin{array}{l}2.95^{* *} \\
(0.05)\end{array}$ & $\begin{array}{l}2.83^{* *} \\
(0.08)\end{array}$ & $\begin{array}{l}2.51^{* *} \\
(0.14)\end{array}$ & $\begin{array}{l}2.59^{* *} \\
(0.34)\end{array}$ \\
\hline $\begin{array}{l}\text { District fixed effects } \\
\text { Fthnicity fixed effects }\end{array}$ & No & $\mathrm{No}$ & $\mathrm{No}$ & $\begin{array}{l}\text { Yes } \\
\text { Yes }\end{array}$ \\
\hline Observations & 3468 & 3468 & 3407 & 3364 \\
\hline Adjusted $R^{2}$ & 0.01 & 0.03 & 0.01 & 0.07 \\
\hline
\end{tabular}

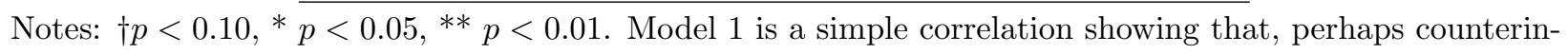
tuitely, those living in district that are part of traditional kingdoms are not more attached to their ethnicity. Model 2 is a linear regression that explores variation in ethnic attachment between subregions (as in Figure 3 ) because it is a more fine-grained unit than regions and yet it is interesting and feasible to include each fixed effect in a table - unlike listing a coefficient for each of the districts. Model 3 is a linear regression that includes only individual covariates. Model 4 is model 3 with district and ethnic group fixed effects. The adjusted $R^{2}$ for a model with only district (ethnic group) fixed effects is $0.063(0.035)$. 
Table 8: Summary statistics for the complete dataset

\begin{tabular}{lccccc}
\hline \hline \multicolumn{1}{c}{ Variable } & Mean & Std. Dev. & Min. & Max. & N \\
\hline Regionalism & 2.019 & 0.805 & 1 & 4 & 3320 \\
Ethnic attachment & 2.902 & 0.992 & 1 & 5 & 3468 \\
District ethnic majority & 0.745 & 0.436 & 0 & 1 & 3484 \\
Kingdom & 0.304 & 0.46 & 0 & 1 & 3484 \\
Ethnic distance index & 2.972 & 1.279 & 0 & 4 & 3484 \\
Wealth index & 3.327 & 0.893 & 1 & 5 & 3435 \\
Quality of services & 4.037 & 0.695 & 1.375 & 5.875 & 3296 \\
Days of work/month & 9.550 & 12.102 & 0 & 31 & 3466 \\
Trust in coethnics & 3.208 & 0.832 & 1 & 4 & 3465 \\
Trust in LC3 & 3.067 & 0.886 & 1 & 4 & 3305 \\
Trust in NRM & 2.891 & 1.093 & 1 & 4 & 3369 \\
Corruption & 1.953 & 1.425 & 1 & 5 & 3435 \\
Age & 34.427 & 12.056 & 18 & 64 & 3476 \\
Male & 0.485 & 0.5 & 0 & 1 & 3484 \\
Years of education & 7.031 & 4.067 & 0 & 19 & 3480 \\
\hline
\end{tabular}

Table 9: Summary statistics for matched data

\begin{tabular}{lccccc}
\hline \hline \multicolumn{1}{c}{ Variable } & Mean & Std. Dev. & Min. & Max. & N \\
\hline Regionalism & 1.982 & 0.801 & 1 & 4 & 1584 \\
Ethnic attachment (3 categories) & 1.874 & 0.769 & 1 & 3 & 1625 \\
District ethnic majority & 0.702 & 0.457 & 0 & 1 & 1625 \\
Kingdom & 0.29 & 0.454 & 0 & 1 & 1625 \\
Ethnic distance index & 2.955 & 1.264 & 0 & 4 & 1625 \\
Wealth index & 3.218 & 0.841 & 1 & 5 & 1625 \\
Quality of services & 4.093 & 0.680 & 1.375 & 5.875 & 1625 \\
Days of work/month & 10.88 & 12.286 & 0 & 31 & 1625 \\
Trust in coethnics & 3.222 & 0.812 & 1 & 4 & 1625 \\
Trust in LC3 & 3.083 & 0.887 & 1 & 4 & 1625 \\
Trust in NRM & 2.978 & 1.053 & 1 & 4 & 1625 \\
Corruption & 1.924 & 1.42 & 1 & 5 & 1625 \\
Age & 34.59 & 11.633 & 18 & 64 & 1625 \\
Male & 0.516 & 0.5 & 0 & 1 & 1625 \\
Years of education & 6.859 & 3.829 & 0 & 17 & 1625 \\
\hline
\end{tabular}


Table 10: Codebook

\begin{tabular}{ll}
\hline \hline \multicolumn{1}{c}{ Variable } & Description \\
\hline Regionalism & $1=$ centralism, $2=$ autonomism, $3=$ federalism, $4=$ secessionism \\
Ethnic attachment & Increasing (1-5) in attachment to ethnic group over Ugandan identity \\
Regional ethnic majority & 1 if respondent belongs to the largest ethnic group; 0 otherwise \\
Kingdom & 1 if respondent lives in an area where there is a kingdom, 0 otherwise \\
Ethnic distance index & Number of characteristics shared with Museveni: \\
& ethnicity, religion, language and region \\
Wealth index & Composite of 6 measures: food, clean water, medicines, \\
& fuel for cooking, cash income and school expenses \\
& $1=$ always lacked all of the above; $5=$ never lacked any of the above \\
Quality of services & Composite of ease of access to 6 government services: \\
& identity document, piped water, electricity, primary school, \\
& medical treatment and police. $1=$ excellent; $6=$ does not exist \\
Days of work/month & Number of days worked in the last month \\
Trust in co-ethnics & For all trust measures: $1=$ do not trust and $5=$ trust a lot \\
Trust in LC3 & Trust in Local Council Chairman $(1-5)$ \\
Trust in NRM & Trust in National Resistance Movement $(1-5)$ \\
Political corruption & $1-5$ where 1 = Strongly agree to "current government leaders take \\
& government money to benefit themselves and their friends" \\
& $5=$ Strongly agree to "current government leaders use \\
government money to benefit everyone in the country" \\
Age
\end{tabular}




\section{Vignettes}

Figure 7: Daily Monitor Cartoon, July 272012

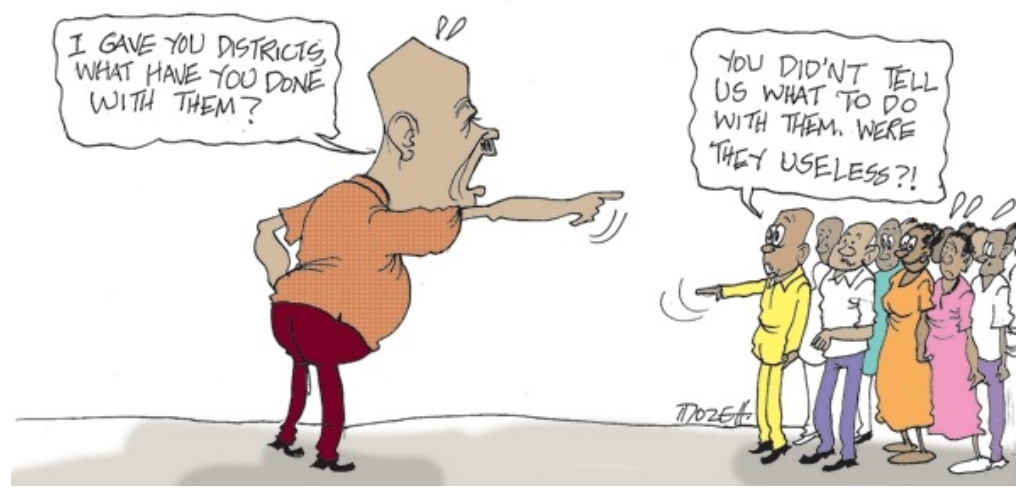

Figure 8: Daily Monitor Cartoon, July 282012

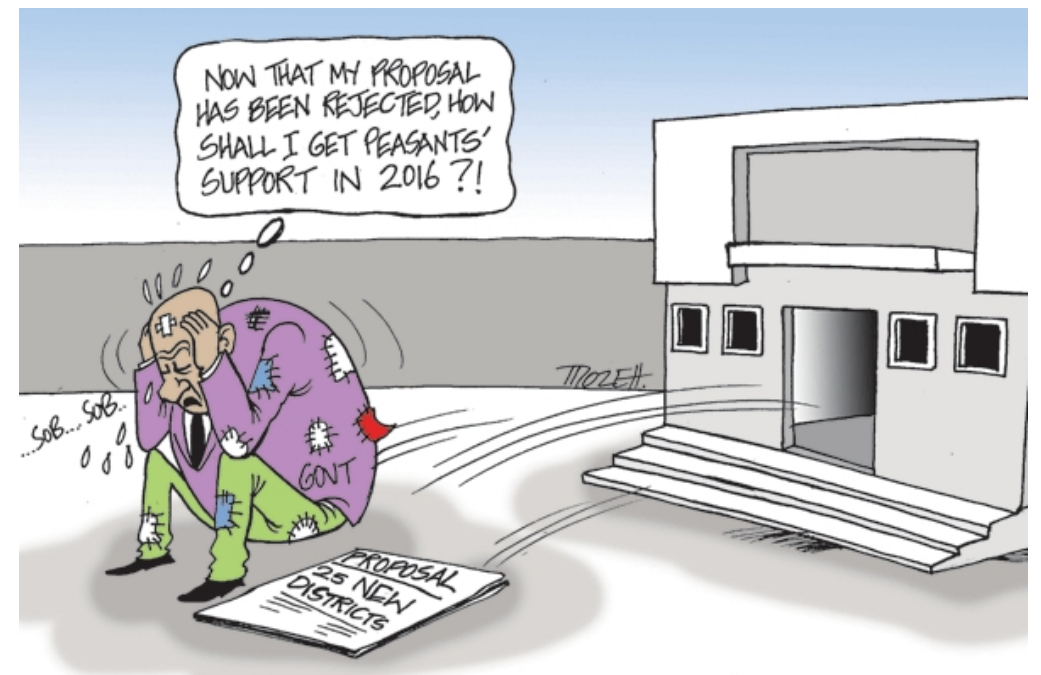

Note: The vignette of July 27th alludes to the financial under-provision that districts suffer, which handicaps the improvement of service provision at the local level - one of the original motivations to create districts in the first place. The vignette of July 28th captures the conflict between the legislature and the executive, resulting from the perceived clientelistic use of new districts by the executive. 